REVISTA DE DERECHO UNED, NÚM. 17, 2015

\title{
TRANSPARENCIA Y CORRUPCIÓN. LA PERCEPCIÓN SOCIAL ANTE COMPORTAMIENTOS CORRUPTOS
}

\author{
TRANSPARENCY AND CORRUPTION. THE SOCIAL PERCEPTION \\ BEFORE CORRUPT BEHAVIORS
}

\begin{abstract}
Juan Manuel Goig Martínez*
"... como sabemos, infraestructura no es solo cuestión de carreteras, escuelas y redes de energía. Es, asimismo, el fortalecimiento de la gobernanza democrática y el Estado de Derecho. Sin transparencia, no solo desde el gobierno hacia el pueblo, sino también entre el propio pueblo, no hay esperanzas de conseguir un Estado democrático viable...»
\end{abstract}

Ban Ki-moon, Secretario General de las Naciones Unidas. Observaciones del Consejo de Seguridad sobre

Timor-este. 19 de febrero de 2009

Resumen: Las modernas democracias constitucionales no sólo deben garantizar reglas claras y confiables para la competencia electoral y el acceso al poder, además, deben asegurar un ejercicio transparente de la función pública, de tal modo que la sociedad pueda conocer y evaluar la gestión gubernamental y el desempeño de los servidores públicos. El éxito de las políticas de transparencia depende de que la información sea accesible y comprensible, y esté disponible para todos.

Summary: The modern constitutional democracies must not only ensure clear and reliable rules for the electoral competition and access to power, they must also ensure a transparent exercise in the public service, so that society can learn about and assess the govern-

* Profesor de Derecho Constitucional. Departamento de Derecho Político. UNED 
ance and performance of public servants. The success of the policy of transparency depends on that information is accessible and comprehensible, and available for all.

Palabras clave: transparencia, corrupción, democracia, acceso a la información.

Keywords: transparency, corruption, democracy, access to the information.

Recepción original: 7/09/2015

Aceptación original: 5/10/2015

Sumario: 1. Transparencia vs. corrupción: concepto, origen y desarrollo. 2. Transparencia y democracia. 3. Acceso a la información como medida principal de transparencia. 4. Las exigencias de transparencia en el orden internacional. 5. El tratamiento de la transparencia en España: 5.1. La Ley de transparencia, acceso a la información pública y buen gobierno. 6. transparencia internacional. La percepción de corrupción en el mundo. El caso español: 6.1. Los resultados de España en el IPC 2014.

\section{TRANSPARENCIA VS. CORRUPCIÓN: CONCEPTO, ORIGEN Y DESARROLLO}

Transparencia es la obligación de los poderes públicos de poner a disposición de todos sus gobernados la información que muestre la estructura y el funcionamiento de cada órgano gubernamental en el ejercicio de sus atribuciones. La transparencia tiene por objeto, por un lado, producir un ambiente de confianza, seguridad y veracidad entre el gobierno y la sociedad, y por otro, formar a una ciudadanía responsable y participativa, que conozca y ejerza sus derechos y obligaciones, y colabore activamente en el fomento a la integridad y combata la corrupción, puesto que están informados y conocen las responsabilidades, procedimientos, reglas, normas y demás información generada por el sector público, en un marco de abierta participación social y escrutinio de carácter público.

El término opuesto a corrupción política es transparencia. Por esta razón se puede hablar del nivel de corrupción o de transparencia de un Estado.

Se define la corrupción como el mal uso o el abuso del poder público para beneficio personal y privado, hecho que no tiene porqué ceñirse a los detentadores del poder o a los funcionarios, aunque por 
lo general lo vinculamos a los gobernantes o los funcionarios elegidos o nombrados, que se dedican a aprovechar los recursos públicos para, de una u otra forma, enriquecerse o beneficiar a parientes o amigos.

Las causas de la corrupción ${ }^{1}$ pueden ser endógenas (internas) o exógenas (externas):

- Entre las muchas causas endógenas (las que tienen que ver con el individuo) podemos indicar las siguientes:

- Carencia de una conciencia social.

- Falta de educación o de una cultura del compromiso.

- Paradigmas distorsionados y negativos.

- Personalidades antisociales y megalomanía.

- Percepción sesgada del grado de corrupción presente.

- Infravaloración de la posibilidad de ser descubierto.

- Como elementos exógenos de la corrupción (los que dependen de la sociedad), pueden citarse:

- Impunidad efectiva en los actos de corrupción.

- Corporativismo partidista.

- Modelos sociales que transmiten una falta de valores.

- Excesivo poder discrecional del funcionario público.

- Concentración de poderes y de decisión en ciertas actividades del gobierno.

- Discrecionalidad y escasez de decisiones colegiadas.

- Soborno internacional.

- Control económico o legal sobre los medios de comunicación que impiden que se expongan a la luz pública los casos de corrupción.

- Salarios demasiado bajos.

- Falta de transparencia en la información concerniente a la utilización de los fondos públicos y de los procesos de decisión.

- Poca eficiencia de la administración pública.

- Extrema complejidad del sistema.

${ }^{1}$ Vid. BEGOVIC, B. Corrupción: conceptos, tipos, causas y consecuencias, Documentos de CADAL, Año III. Número 26, 1 de marzo de 2005. 
Respecto a sus efectos, la corrupción dificulta que un país mejore en su economía, ya que evita la competencia y la libre concurrencia entre proveedores en igualdad. Aumenta la sensación de injusticia y crea desafección de los ciudadanos a un sistema que pueden llegar a percibir como contrario o desapegado a los intereses generales. La corrupción lastra la confianza general, dificultando la confianza hacia las instituciones, y evita el desarrollo de conductas cooperativas generales. Tiene, por consiguiente, efectos económicos, políticos e institucionales ${ }^{2}$.

Los orígenes de la rendición de cuentas por parte del gobierno (government accountability) como comúnmente es conocida hoy, se encuentran no en la cultura occidental, sino en la civilización oriental, en concreto en el período de mayor esplendor de la dinastía Ch'ing ${ }^{3}$.

La primera ley formal de acceso a la información fue la Freedomof-press and the Right-of-access to public records act (Ley para la Libertad de Prensa y del Derecho de Acceso a las Actas Públicas) aprobada en Suecia en 1766, diez años antes de la Independencia de los Estados Unidos y trece antes de la Revolución Francesa.

La idea del acceso sin restricciones a los documentos públicos tardaría en cobrar toda su fuerza hasta dos siglos después -con la excepción de la regulación colombiana de 1888-: en Finlandia (1951), en Estados Unidos (1966) y en Dinamarca (1970), para volverse luego parte de la oleada democratizadora en los últimos cinco años del siglo XX, y se ha convertido en un fenómeno de gran magnitud y universalidad.

De la primera ley en el mundo, en Suecia, que data de 1766, a las más recientes reformas en Indonesia y Rusia, de 2010, o España 2013, han pasado 247 años. Con todo, en 247 años se han aprobado más de 80 leyes nacionales o federales, 184 estatales y dos de organismos internacionales. Esto representa $41 \%$ de los países reconocidos por la ONU. Del año 2000 a la fecha se han aprobado 55, es decir el $66 \%$ de las aprobadas en el mundo. En África sólo cuatro naciones cuentan con reglamentaciones de acceso a la información, todas sancionadas a partir del 2000. En América, 17 Estados dispo-

${ }^{2}$ Vid. LIZCANO ÁLVAREZ, J. Ciencia, economía y transparencia: una visión en clave multidisciplinar y social, Discurso de ingreso en la Real Academia de Ciencias Económicas y Financieras, como académico correspondiente para Madrid y discurso de contestación, Barcelona, Real Academia de Ciencias Económicas y Financieras, 2015.

${ }^{3}$ LAMBLE, S. «Freedom of Information, a Finnish clergyman's gift to democracy,» Freedom of Information Review, no. 97, 2002, págs. 2 a 8. 
nen de normativa en la materia, siendo la de 1966, en Estados Unidos, la más antigua. En Asia hay 19 leyes, incluida la reciente Ley de Acceso de China aprobada en 2007 y reformada en 2008. En Europa 38 países cuentan con legislaciones sobre transparencia, 18 de las cuales fueron aprobadas también a partir del 2000. En Oceanía son tres los países que disponen de ese recurso. La aprobación del Código de Prácticas en materia de transparencia del Fondo Monetario Internacional de 2002, así como de su proyecto previo de 1999, contribuyeron, en gran medida, a la aparición de leyes basadas en el reconocimiento del derecho a la información como derecho fundamental reconocido en la Declaración Universal de Derechos Humanos de $1948^{4}$.

El hecho de que se hayan aprobado leyes sobre acceso a la información no significa que los Estados cumplan con su deber de informar, y que las personas ejerzan realmente su derecho a saber.

\section{TRANSPARENCIA Y DEMOCRACIA}

$\mathrm{BOBBIO}^{5}$ ha indicado cómo «es bien conocido que la democracia nació bajo la perspectiva de erradicar para siempre de la sociedad humana el poder invisible para dar vida a un gobierno cuyas acciones deberían haber sido analizadas en público. Una de las razones de la superioridad de la democracia con respecto a los Estados absolutos que habían reivindicado los "arcani imperi», y defendían con argumentos históricos y políticos la necesidad de que las grandes decisiones políticas fuesen tomadas en los gabinetes secretos, lejos de las miradas indiscretas del público, está basada en la convicción de que el gobierno democrático pudiese finalmente dar vida a la transparencia del poder, al «poder sin máscaras»».

Como ha afirmado DE LUCAS, no hay representación real, ni participación posible, ni, en definitiva, legitimidad democrática, sin principio de publicidad, porque, por otra parte, no hay control donde no hay transparencia, y sin control eficaz del poder no cabe la democra$\mathrm{cia}^{6}$. Por eso, parece tener razón $\mathrm{HABERMAS}^{7}$ cuando sostiene que

${ }^{4}$ Vid. ACKERMAN, J. M. y SANDOVAL, I. E. Leyes de acceso a la información en el Mundo, en Cuadernos de Transparencia, n. ${ }^{\circ}$ 7, IFAI.

${ }^{5}$ BOBBLIO, N. El futuro de la Democracia, Fondo de Cultura Económica, México, 1986.

${ }^{6}$ DE LUCAS MARTÍN, J. «Democracia y transparencia. Sobre poder, secreto y publicidad», en ANUARIO DE FILOSOFIA DEL DERECHO VII (1990) 131.145

${ }^{7}$ HABERMAS. Historia y crítica de la opinión pública. G. Gilli, Barcelona, 1981, pág. 139.

(C) UNED. Revista de Derecho UNED, núm. 17, 2015 
no cabe hablar de ciudadanía hasta tanto la publicidad política activa se convierte en principio organizativo del Estado

Democracia y transparencia son términos que se evocan recíprocamente. Un régimen democrático es, por supuesto, mucho más que un sistema en el que el ciudadano participa a través del voto; es también aquel en el que, además, hay una amplia participación y una estrecha vinculación entre la estructura estatal creada para servir al hombre mismo, que haga factible la realización de los fines perseguidos al crearla.

La transparencia está vinculada tanto a la participación democrática como al control democrático. El término más amplio y flexible de transparencia pública, incluye todas aquellas actividades y medios dirigidos a evitar el alejamiento de la Administración por opacidad y mostrar la apertura de la Administración a sus ciudadanos, y entre ellos, ocupa un lugar especial el acceso a la información pública ${ }^{8}$.

La democracia exige participación, y para participar hay que estar informado, y en este sentido, el Tribunal Constitucional español, desde sus primeras decisiones, ha reconocido en la formación de una opinión pública libre uno de los requisitos esenciales de una democracia (SSTC 6/1981, de 6 de marzo; 12/1982, de 31 de marzo; $56 / 1983$, de 28 de junio... entre otras). La democracia requiere transparencia en la actuación de las instituciones públicas, pues permite el acceso de los ciudadanos a la información y garantiza la ausencia de arbitrariedad en el ejercicio del poder público. Pero además, la transparencia es un requisito necesario para el ejercicio del derecho fundamental a la participación en asuntos públicos y facilita el control social de la actividad de los poderes públicos ${ }^{9}$.

Las modernas democracias constitucionales no sólo deben garantizar reglas claras y confiables para la competencia electoral y el acceso al poder, además, deben asegurar un ejercicio transparente de la función pública, de tal modo que la sociedad pueda conocer y evaluar la gestión gubernamental y el desempeño de los servidores públicos.

${ }^{8}$ Vid. COTINO HUESO, L. «Transparencia y derecho a la información pública en la Unión Europea. ¿De valor en alza a derecho fundamental?», comunicación presentada en IV Jornadas Internacionales sobre derechos y libertades fundamentales. (Los derechos fundamentales en la Unión Europea). 7-8 Noviembre, 2002, Zaragoza, págs. 4 a 6.

${ }^{9}$ Vid. TRONCOSO REIGADA, A. «Acceso a la información administrativa y protección de datos personales», en TRONCOSO (Dir.), Transparencia administrativa y protección de datos, Madrid, Thomson-Civitas, 2008, especialmente págs. 35 a 39. 
La transparencia de la actividad pública es una manifestación y un requisito típico de los sistemas democráticos, que tiene como objetivo el sometimiento al escrutinio público de las actividades y resultados de los distintos poderes del Estado. En un Estado Democrático, la actividad de los tres órdenes de gobierno (Ejecutivo, Legislativo y Judicial) deben regirse por el principio de publicidad.

Transparencia es «abrir la información de las organizaciones políticas y burocráticas al escrutinio público, mediante sistemas de clasificación y difusión que reducen los costos de acceso a la información del gobierno. La transparencia no es el acto de rendir cuentas a un destinatario específico, sino la práctica de colocar la información en la vitrina pública para que todos puedan revisarla, analizarla y, en su caso, usarla como mecanismo para sancionar, en caso de haya, anomalías en su interior.

La transparencia exige:

- Fácil acceso a la información, incluyendo oportunidad y no discriminación.

- Tratamiento comprensivo que asegure que los temas clave no queden fuera.

- Relevancia, evitando la información superflua y el sobreflujo de información, y

- Calidad y confiabilidad para contribuir al diseño de políticas y dar confianza en los mercados para los inversionistas.

El éxito de las políticas de transparencia depende de que la información sea accesible y esté disponible para todos los usuarios. Una política pública es transparente si es comprensible, si la información está disponible, si la rendición de cuentas es clara y si los ciudadanos saben qué papel desempeñan en dicha política. Es precisamente en este punto donde aparece el derecho al acceso a la información, cuya finalidad es mejorar la calidad de vida de los ciudadanos, ofreciendo el poder de la información para su uso cercano y personal, todo ello dando forma, contenido y sentido al derecho a la información en general.

\section{ACCESO A LA INFORMACIÓN COMO MEDIDA PRINCIPAL DE TRANSPARENCIA}

En el actual grado de evolución democrática, la exigencia de una mayor transparencia de la actuación de los poderes públicos, se ha generalizado. 
Uno de los indicadores objetivos de la calidad democrática de una sociedad es la transparencia de sus instituciones públicas. Ello sólo es posible a través de una adecuada protección, constitucional y legal, del derecho de acceso a la información pública, entendido como un instrumento para el control democrático del ejercicio del poder. El derecho de acceso garantiza, en este sentido, la responsabilidad y la rendición de cuentas de las instituciones públicas; previene frente a la arbitrariedad de la Administración; posibilita la participación ciudadana en el proceso de toma de decisiones públicas; garantiza el ejercicio de otros derechos, y constituye uno de los pilares de un gobierno abierto a sus ciudadanos. Como corolario del derecho a la información, el derecho a saber favorece una opinión pública informada e ilustrada. En democracia, la ratio última de las leyes de acceso a la información debe ser el máximo acceso posible, mientras que la retención de información sólo podrá aplicarse sobre la base de excepciones legalmente tasadas e interpretadas de forma estricta ${ }^{10}$.

El acceso a la información pública es un requisito indispensable para el funcionamiento mismo de la democracia. Implica una mayor transparencia y una buena gestión pública. En un sistema democrático representativo y participativo, la ciudadanía ejerce sus derechos constitucionales de participación política, votación, educación y asociación, entre otros, a través de una amplia libertad de expresión y de un libre acceso a la información ${ }^{11}$.

En una sociedad democrática, el derecho a la información constituye un presupuesto de la transparencia, que refuerza la confianza de la ciudadanía en los gobiernos y en las administraciones públicas. El acceso a los documentos ofrece al público una visión de conjunto, que permitiría la formación de una opinión crítica sobre el estado de la sociedad y las autoridades, de modo que evitaba la corrupción.

En el ámbito del Consejo de Europa, dos Recomendaciones ponen de manifiesto el interés por la transparencia. La primera adoptada en noviembre de 1981, considera que el acceso del público a la información, refuerza su confianza en la administración, debiendo asegurarse el acceso a la documentación en manos de las autoridades públicas. La segunda recomendación fue adoptada en febrero de 2002, y considera, entre otros aspectos, la importancia, en una sociedad democrá-

${ }^{10}$ GUTIÉREZ DAVID, E. «Derecho de acceso a la información pública» en EUNOMIA. Revista en cultura de la legalidad, n. ${ }^{\circ}$ 6, marzo-agosto de 2014, págs. 186-196.

${ }^{11}$ Resolución Acceso a la información pública: fortalecimiento de la democracia [AG/RES. 1932 (XXXIII-O/03)], de la Asamblea General de la Organización de Estados Americanos. 
tica, de una administración pública transparente, y la disponibilidad de información sobre cuestiones de interés público ${ }^{12}$.

Ha habido una progresiva evolución en el fortalecimiento del derecho de acceso a la información pública, que ha tenido un punto de inflexión en el año 2009, en el que han coincidido su reconocimiento por el Tribunal Europeo de Derechos Humanos como integrante del derecho fundamental a la libertad de expresión e información consagrada en el artículo 10 del Convenio Europeo de Derechos Humanos (en adelante, $\mathrm{CEDH}$ ); y su regulación mediante un instrumento vinculante, el Convenio núm. 205 del Consejo de Europa sobre acceso a los documentos públicos (en adelante, Convenio 205),

En el Preámbulo del Convenio 205 se hace especial referencia a la importancia de la transparencia de la actividad de las autoridades públicas, manifestando que el ejercicio del derecho de acceso a los documentos públicos proporciona una fuente de información para el público, el cual puede, a partir de los mismos, formarse una opinión sobre el estado de la sociedad y de la autoridades públicas, fomentándose la integridad, la eficacia, la eficiencia y la responsabilidad de las autoridades públicas.

$\mathrm{El}$ acceso a los documentos preparatorios que reflejan los procesos de toma decisiones políticas y legislativas obliga a las instituciones no sólo a asumir la responsabilidad frente a los ciudadanos de las decisiones que toman, sino también a justificar la racionalidad y el interés público existente detrás de la propia decisión (STJUE asunto Access Info Europe/Consejo, de 22 de marzo de 2011).

Por supuesto, la existencia de reconocimiento constitucional y de leyes de acceso a la información y cuáles sean sus niveles de «densidad normativa» no es el único dato a considerar. A su mayor o menor ambición de transparencia, complitud, calidad jurídica y adaptación a las nuevas realidades tecnológicas se une una mayor disparidad en el grado de implementación- en especial, en relación con la gestión de la información, la publicidad activa o las garantías- y en el propio ejercicio ciudadano del derecho de acceso y la mayor o menor tradición democrática y de transparencia.

Las medidas de transparencia y acceso a la información no se agotan, desde luego, en el acceso a los documentos, que, a la postre, es un instrumento «de lujo» utilizado fundamentalmente por actores cualificados, y no por «el común de los ciudadanos», sino que tras-

${ }^{12} \mathrm{Vid}$. QUIRÓS SORO, MF. «La transparencia en la Unión Europea», en MEI (Métodos de Información), II, Vol. 3, n. ${ }^{\circ}$ 5, 2012 págs. 190-191.

(C) UNED. Revista de Derecho UNED, núm. 17, 2015 
ciende para incluir la publicidad de las sesiones de los órganos constitucionales o la publicidad oficial. Más en general, debe hablarse de una auténtica "política de comunicación»

El derecho de acceso a la información pública es un derecho fundamental que conlleva un "reapoderamiento" de los ciudadanos. No es necesario ser parte del expediente, ni tener un interés legítimo para tener acceso a la información pública. Basta con querer saber, porque la información en manos de los poderes públicos pertenece a todos.

Por ello, toda medida que regule el acceso a la información debe garantizar, al menos, los siguientes principios básicos:

- Que los sujetos obligados no sólo deben ser las instituciones públicas, sino cualquier persona física o jurídica que ejerza funciones de la Administración, preste servicios públicos, o reciba o gestione ayudas públicas.

- Que el ciudadano no tiene que acreditar ningún interés legítimo para ejercer el derecho de acceso a la información pública.

- Que la solicitud y la tramitación del procedimiento de acceso se caracterizará por el antiformalismo, la gratuidad, y la elección del medio para el acceso (electrónico o no) por el solicitante. Los principios de asistencia y publicidad pro-activa, de interpretación favorable al acceso y restrictiva de la excepción deberán guiar la actuación administrativa.

- Que las excepciones deberán estar legalmente tasadas, la Administración motivará adecuadamente las denegaciones de acceso y deberá garantizarse, en su caso, el acceso parcial. Los plazos de contestación administrativa a las solicitudes de acceso habrán de ser cortos, y la falta de contestación en el plazo establecido deberá entenderse como desestimatoria de la solicitud de acceso.

- Que, sin perjuicio del oportuno control judicial, una autoridad independiente revisará las denegaciones de acceso.

Entendido así el derecho de acceso a la información pública, éste garantiza la transparencia, la responsabilidad y la rendición de cuentas de las instituciones públicas; previene frente a la arbitrariedad de la Administración y permite la participación ciudadana en el proceso de toma de decisiones públicas; garantiza el ejercicio de otros derechos fundamentales; y constituye uno de los pilares de un gobierno abierto a sus ciudadanos posibilitando el control democrático del poder. 
Pero el derecho a ser informado sobre asuntos generales, como contenido del artículo 20.1.d) CE, no ha sido concebido como un derecho de carácter prestacional. Se dirige fundamentalmente a evitar la injerencia en el libre flujo de la información ${ }^{13}$. Y no es un derecho ilimitado, ni incluye un derecho ilimitado de búsqueda y obtención de la información, solo cubre el derecho a recibir información sobre aquello que es de "interés público», y aun así, no siempre. La Constitución no impone la publicidad absoluta de toda actuación de los poderes públicos, -incluso en aspectos tan principales como el derecho a un proceso judicial público podemos encontrar excepciones a dicha publicidad- ${ }^{14}$. Evidentemente, deben de existir, precisamente en protección de otros derechos fundamentales y otros bienes constitucionalmente protegidos, límites al ejercicio de acceso a datos e información.

No obstante, también debemos afirmar que el hecho de que existan límites, no implica que, automáticamente, el régimen jurídico concreto de regulación de los mismos y su uso deba quedar exento de control $^{15}$. Es decir, que frente a derechos fundamentales sagrados en nuestra Constitución, no puede prevalecer ninguna "razón de Estado» y que las materias clasificas no pueden considerarse como una zona de inmunidad jurisdiccional.

Si traemos ese mismo razonamiento a la resolución del conflicto entre la necesidad de que el Estado cumpla con sus funciones de salvaguardar la seguridad y lleve a cabo sus actuaciones con carácter secreto, por un lado, y, el derecho de los ciudadanos a ser informados de ello, por otro, la decisión debe de ser proporcional, y también hemos de acudir al juicio constitucional de la ponderación, como elemento integrante de la proporcionalidad.

\section{LAS EXIGENCIAS DE TRANSPARENCIA EN EL ORDEN INTERNACIONAL}

En el Orden Internacional ha existido una constante preocupación por temas de corrupción y democracia.

${ }^{13}$ Entre otras, SSTC 105/1990, de 6 de junio; 172/1990, de 5 de noviembre; 240/1992, de 21 de diciembre.

${ }^{14}$ Un interesante estudio sobre límites a la información puede verse en SERRA CRISTÓBAL, R., «La opinión pública ante la vigilancia masiva de datos. El difícil equilibrio entre acceso a la información y seguridad nacional», en Revista de Derecho Político, N. ${ }^{\circ}$ 92, enero-abril 2015, págs. 73-118.

${ }^{15}$ Vid. entre otras STS de 4 de abril de 1997. 
Son varios los Tratados y Convenciones en el orden Internacional destinados a luchar contra la corrupción: la Convención Interamericana contra la Corrupción, aprobada por la Organización de los Estados Americanos el 29 de marzo de 1996 ${ }^{16}$; el Convenio relativo a la lucha contra los actos de corrupción en los que estén implicados funcionarios de las Comunidades Europeas o de los Estados Miembros de la Unión Europea, aprobado por el Consejo de la Unión Europea el 26 de mayo de 1997'7; el Convenio sobre la lucha contra el soborno de los funcionarios públicos extranjeros en las transacciones comerciales internacionales, aprobado por la Organización de Cooperación y Desarrollo Económicos el 21 de noviembre de 199718; el Convenio de derecho penal sobre la corrupción, aprobado por el Comité de Ministros del Consejo de Europa el 27 de enero de 199919; el Convenio de derecho civil sobre la corrupción, aprobado por el Comité de Ministros del Consejo de Europa el 4 de noviembre de 1999; la Convención de la Unión Africana para prevenir y combatir la corrupción, aprobada por los Jefes de Estado y de Gobierno de la Unión Africana el 12 de julio de 2003, o la Convención de las Naciones Unidas contra la Delincuencia Organizada Transnacional, de 29 de septiembre de $2003^{20}$.

En Naciones Unidas, la gobernanza se considera «buena» y «democrática» en la medida en que las instituciones y procesos de cada país sean transparentes. Los procesos democráticos incluyen como actividades fundamentales las elecciones y los procesos legales, los cuales deben estar exentos de corrupción y deben ser responsables ante el pueblo. El cumplimiento de esta normativa se ha convertido en un baremo imprescindible para medir la credibilidad y el respeto de los países en el panorama mundial.

La buena gobernanza promueve la equidad, la participación, el pluralismo, la transparencia, la responsabilidad y el Estado de Derecho, de modo que el modelo sea efectivo, eficiente y duradero, lo que exige elecciones periódicas, libres y limpias, parlamentos representativos que redactan leyes y proporcionan una visión de conjunto, y un sistema jurídico independiente para interpretar dichas leyes.

${ }^{16}$ Véase E/1996/99.

${ }^{17}$ Diario Oficial de las Comunidades Europeas, C 195, 25 de junio de 1997.

${ }^{18}$ Véase Corruption and Integrity Improvement Initiatives in Developing Countries (publicación de las Naciones Unidas).

${ }^{19}$ Consejo de Europa, European Treaty Series, N. ${ }^{\circ} 173$.

${ }^{20}$ Resolución 55/25 de la Asamblea General, anexo I. 
La mayor amenaza para la buena gobernanza viene de la corrupción, la violencia y la pobreza, todo lo cual debilita la transparencia, la seguridad, la participación y las libertades fundamentales.

La gobernanza democrática fomenta el desarrollo, dedicando su energía a influir en tareas como la erradicación de la pobreza, la protección del medio ambiente, garantizar la igualdad entre los géneros y proporcionar los medios de subsistencia sostenibles. Garantiza que la sociedad civil desempeñe un papel activo al establecer prioridades y dar a conocer las necesidades de los sectores más vulnerables de la sociedad.

La Convención de las Naciones Unidas contra la Corrupción, de octubre de 2003 (con entrada en vigor en 2005) ha puesto de manifiesto:

- La amenaza que plantea la corrupción para la estabilidad y seguridad de las sociedades al socavar las instituciones y los valores de la democracia, la ética y la justicia y al comprometer el desarrollo sostenible y el imperio de la ley,

- Que los casos de corrupción que entrañan vastas cantidades de activos de los recursos de los Estados, amenazan la estabilidad política y el desarrollo sostenible de esos Estados,

- Que la corrupción ha dejado de ser un problema local para convertirse en un fenómeno transnacional que afecta a todas las sociedades y economías, lo que hace esencial la cooperación internacional para prevenirla y luchar contra ella,

- Que se requiere un enfoque amplio y multidisciplinario para prevenir y combatir eficazmente la corrupción,

- Que la prevención y la erradicación de la corrupción son responsabilidad de todos los Estados y que éstos deben cooperar entre sí, con el apoyo y la participación de personas y grupos que no pertenecen al sector público, como la sociedad civil, las organizaciones no gubernamentales y las organizaciones de base comunitaria, para que sus esfuerzos en este ámbito sean eficaces.

En el ámbito de la UE, desde los inicios de la construcción europea, encontramos en los Tratados constitutivos manifestaciones relativas a la transparencia de las instituciones comunitarias ${ }^{21}$. Sin embargo la transparencia en las instituciones europeas ha estado ausente durante décadas, pues no han existido mecanismos para articularla.

${ }^{21}$ Vid. QUIRÓS SORO, MF. «La transparencia en la Unión Europea», en MEI (Métodos de Información), II, Vol. 3, n. ${ }^{\circ}$ 5, 2012 págs. 188-190. 
El Consejo Europeo celebrado en Birmingham en octubre de 1992, mediante la declaración, «Una Comunidad cercana a sus ciudadanos», ya estimó necesaria la transparencia de la Comunidad "para garantizar un debate público mejor informado sobre sus actividades», así como la proximidad a los ciudadanos en la adopción de las decisiones.

La Declaración n. ${ }^{\circ} 17$ aneja al Acta final del Tratado de la Unión Europea firmado en Maastricht, constituye el punto de partida en materia de transparencia. El objeto de la Unión Europea consiste en obtener la confianza de las personas en las instituciones y órganos comunitarios. La celebración de sucesivos Consejos Europeos sentaron las bases de la política sobre la transparencia comunitaria.

Se aprobaron los Códigos de acceso a los documentos del Consejo y de la Comisión, cuyos principios inspiraron las normas vinculantes en dicha materia, que adoptaron otras instituciones, órganos y organismos comunitarios.

El Tratado de Ámsterdam inaugura una nueva etapa en materia de transparencia, al introducir el principio de apertura en la toma de decisiones, así como al declarar el derecho de acceso a los documentos del Parlamento, del Consejo y de la Comisión, además de establecer los medios de impugnación frente a resoluciones denegatorias de solicitudes de acceso ${ }^{22}$. Ámsterdam introdujo explícitamente el concepto de «apertura» en el preámbulo del Tratado de la Unión Europea indicando que éste constituye una nueva etapa en el proceso creador de una unión cada vez más estrecha entre los pueblos de Europa, en la cual las decisiones serán tomadas de la forma más abierta y próxima a los ciudadanos que sea posible. Esta idea culminó en el Consejo Europeo de Niza en diciembre de 2000, cuando se proclamó la Carta de los Derechos Fundamentales de la Unión Europea.

El Tratado en Lisboa incorpora al Tratado de la Unión Europea, los principios de democracia representativa y participativa y protección de datos personales, (Arts. 10, 11 y 39). El Tratado de Funcionamiento de la Unión Europea, incorpora el principio de apertura y la transparencia en la actuación de instituciones, órganos y organismos de la Unión, el derecho de acceso a los documentos, protección de datos de carácter personal, tratamiento y circulación de los mismos (Arts. 15, 16 y 298.1) y la Carta de los Derechos Fundamentales, a la que Lisboa otorga el mismo valor que a los Tratados (art. 6.1) contiene los derechos de recepción de información, protección y acceso a

\footnotetext{
${ }^{22}$ Reglamento 1049/2001.
} 
datos y expedientes de carácter personal, a la buena administración, obligación de la administración de motivar sus decisiones y acceso a los documentos de las instituciones europeas (Arts. 8, 11, 41 y 42). También la Carta incluye entre los derechos fundamentales del ciudadano «el derecho a una buena administración ${ }^{23}$ y el derecho a someter al Defensor del Pueblo de la Unión los casos de mala administración» (Artículo 4124).

La UE ha puesto su interés en que los ciudadanos pueden y deben esperar que el proceso de toma de decisiones de la UE sea lo más transparente y abierto posible. Cuanto mayor es la apertura, más fácil resulta garantizar una representación equilibrada y evitar presiones abusivas y el acceso ilegítimo o privilegiado tanto a la información como a los responsables de la toma de decisiones. La transparencia es, a su vez, un elemento clave para fomentar la participación activa de los ciudadanos europeos en la vida democrática de la $\mathrm{UE}^{25}$.

Actualmente las actividades de la Unión Europea tienen repercusión en la vida de millones de ciudadanos europeos, por lo que las decisiones que les afectan deben tomarse de la manera más transparente posible. Los ciudadanos europeos tienen derecho a saber cómo

${ }^{23} \mathrm{La}$ «buena administración» como un principio general de Derecho ha sido puesto de manifiesto en varias sentencias de las entidades jurisdiccionales europeas (entre otras, la sentencia del Tribunal de Justicia de 31 de marzo de 1992, C-255/90 P, Burban, Rec. 1992, pág. I-2253; así como las sentencias del Tribunal de Primera Instancia de 18 de septiembre de 1995, T-167/94, Nölle, Rec. 1995, pág. II-2589; de 9 de julio de 1999, T-231/97, New Europe Consulting y otros, Rec. 1999. pág. II-2403). Las manifestaciones de este derecho enunciadas en los dos primeros apartados se derivan de la jurisprudencia (sentencias del Tribunal de Justicia de 15 de octubre de 1987, asunto 222/86, Heylens, Rec. 1987, pág. 4097, apartado 15; de 18 de octubre de 1989, asunto 374/87, Orkem, Rec. 1989, pág. 3283; de 21 de noviembre de 1991, C-269/90, TU München, Rec. 1991, pág. I-5469, y sentencias del Tribunal de Primera Instancia de 6 de diciembre de 1994, T-450/93, Lisrestal, Rec.1994, pág. II-1177; de 18 de septiembre de 1995, T-167/94, Nölle, Rec. 1995, pág. II-2589).

${ }^{24} 1$. Toda persona tiene derecho a que las instituciones y órganos de la Unión traten sus asuntos imparcial y equitativamente y dentro de un plazo razonable. 2. Este derecho incluye en particular: - el derecho de toda persona a ser oída antes de que se tome en contra suya una medida individual que le afecte desfavorablemente, - el derecho de toda persona a acceder al expediente que le afecte, dentro del respeto de los intereses legítimos de la confidencialidad y del secreto profesional y comercial, - la obligación que incumbe a la administración de motivar sus decisiones. 3. Toda persona tiene derecho a la reparación por la Comunidad de los daños causados por sus instituciones o sus agentes en el ejercicio de sus funciones, de conformidad con los principios generales comunes a los Derechos de los Estados miembros. 4. Toda persona podrá dirigirse a las instituciones de la Unión en una de las lenguas de los Tratados deberá recibir una contestación en esa misma lengua.

${ }^{25} \mathrm{Vid}$. CAMISÓN YAGÜE, J. A. «El Informe Anticorrupción de la Unión Europea», en Teoría y Realidad Constitucional, núm. 32, 2013, págs. 373 a 388. 
preparan esas decisiones las instituciones europeas, quién participa en su elaboración, quién recibe financiación del presupuesto de la UE y en qué documentos se basan la preparación y la adopción de los actos legislativos. También tienen derecho a acceder a esos documentos y a manifestar su opinión, ya sea directa o indirectamente, a través de los intermediarios que les representan.

Tanto la Comisión Europea ${ }^{26}$ como el Parlamento Europeo han compartido a lo largo de su historia los mismos objetivos respecto a la transparencia, aunque con evoluciones diferentes. Tras varias comunicaciones, debates y reglamentos, como el Libro Blanco de la Gobernanza Europea, la Iniciativa Europea a favor de la Transparencia o la creación del Registro de Transparencia, y el Portal de Transparencia, se ha observado un importante cambio de mentalidad en el seno de las instituciones europeas.

No obstante, el Informe de Transparencia Internacional de abril de 2014, aun cuando manifiesta que hay buenas bases en el sistema de la UE para apoyar la integridad y la ética, éstas se ven frecuentemente socavadas por malas prácticas, falta de liderazgo político, falta de personal y fondos y falta de claridad sobre a quién se aplican las reglas. Aunque las instituciones europeas presumen de figurar entre las más transparentes del mundo, se enfrentan a serios riesgos de corrupción, entre los que el Informe destaca la opacidad en la toma de decisiones, la actividad de los grupos de presión, los conflictos de intereses y la falta de protección para quienes denuncian irregularidades impiden que las reglas se cumplan de manera eficaz.

Ya en abril de 2013, el Foro de Europa Ciudadana presenta el informe «Transparencia en la Unión Europea: evolución y perspectivas», en el que se denunciaba que la falta de transparencia en las instituciones europeas aumenta la desconfianza de los ciudadanos europeos hacia las instituciones comunitarias, y presentaba una serie de propuestas para mejorar la transparencia en la Unión Europea y acercarla a los ciudadanos ${ }^{27}$

${ }^{26}$ Vid. COMISIÓN EUROPEA, Comunicación de la Comisión al Parlamento Europeo, al Consejo y al Comité Económico y Social Europeo-Lucha contra la corrupción en la UE, COM (2011) 308 Final, de 6 de junio de 2011. También Comunicación de la Comisión al Parlamento Europeo y al Consejo, COM (2010) 673: «La Estrategia de Seguridad Interior de la UE en acción: cinco medidas para una Europa más segura», en la que se preveía expresamente la presentación de una propuesta específica sobre cómo dirigir y apoyar los esfuerzos de los Estados miembros contra la corrupción.

${ }^{27}$ Entre las propuestas contenidas en el informe de Foro Europa Ciudadana que podrían ayudar a mejorar la transparencia destacan, entre otras:

1. La Unión Europea debe desarrollar una regulación mucho más estricta del llamado fenómeno del «revolving door», la incorporación de ex funcionarios y ex 
Es necesario rediseñar ampliamente la arquitectura política e institucional de la Unión Europea, para garantizar que la cesión de competencias y la transferencia de soberanía de los Estados en los principales ámbitos de actuación económico-financieros vayan acompañadas de un aumento de la legitimidad democrática de las distintas instancias o instituciones europeas. El papel de las instituciones comunitarias en la toma de decisiones conjuntas o colectivas continúa, por lo general, supeditado a las posiciones de algunos Estados miembros (intergubernamentalidad decisoria), lo que supone una cierta pérdida de legitimidad de dichas instituciones e incluso también del proyecto europeo en sí mismo. Junto a ello, es preciso aumentar las cotas de transparencia, y el acceso a la información, puesto que control y legitimidad democrática son elementos indisociables.

\section{EL TRATAMIENTO DE LA TRANSPARENCIA EN ESPAÑA}

Parece clara la insuficiencia de la regulación que ha existido en España sobre transparencia ${ }^{28}$ y acceso a la información pública. La doctrina y el legislador se han decantado todos estos años por enten-

políticos a empresas con intereses en sectores en los que previamente habían estado legislando.

2. La UE debe eliminar todas las restricciones actuales para conocer quiénes son los receptores de las ayudas comunitarias. En la actualidad, las diferentes regulaciones nacionales permiten sólo un conocimiento parcial y disperso. Además, debido al elevado importe de las cuantías de los fondos, puede generar controversia en la opinión pública.

3. La inscripción en el Registro de Transparencia debería ser obligatoria para todas las entidades y personas que interactúan con las instituciones europeas durante el proceso de elaboración de las leyes. Igualmente deberían estar adscritas a este Registro todas las instituciones y agencias comunitarias.

4. Los eurodiputados deberían estar sometidos a criterios de transparencia, de tal manera que se hiciera pública periódicamente información relativa a qué reuniones y contactos ha mantenido durante el proceso de elaboración de una propuesta legislativa. Por ello, tanto la Comisión como el Parlamento deberían hacer pública la relación de reuniones, solicitudes, consultas, opiniones y contribuciones presentadas en los procesos legislativos.

5. La redacción de los cuestionarios de las consultas de la Comisión Europea deberían ser más transparentes, especialmente en lo que se refiere a su formulación, ya que no basta con preguntar de forma genérica y poco concreta, como sucede actualmente en numerosas ocasiones.

${ }^{28}$ En cuanto a la regulación sobre buen gobierno, se está ante una propuesta que sigue el camino de mejora de la "buena administración» y responsabilidad de los agentes públicos abierto en los últimos años es España con la Ley 7/2007, de 12 de abril, del Estatuto Básico del Empleado Público y la Ley 5/2006, de 10 de abril de Regulación de los Conflictos de Intereses de los miembros del Gobierno y los Altos Cargos de la Administración General del Estado. 
der que se está ante un principio de actuación de los poderes públicos que tendría su «enganche» constitucional en el acceso de los ciudadanos a los archivos y registros administrativos (art. 105. b). CE). Así, el artículo 35 de la Ley 30/92 ${ }^{29}$ establece que en sus relaciones con los ciudadanos la Administración pública actúa de conformidad con los principios de transparencia y participación, reconociendo que los ciudadanos tienen los siguientes derechos: conocer, en cualquier momento, el estado de la tramitación de los procedimientos en los que tengan la condición de interesados..., y acceso a la información pública, archivos y registros ${ }^{30}$.

Como ha indicado ARANDA, es cierto que buscar el «ajuste» de la transparencia entre los derechos fundamentales plantea ciertos problemas puesto que la Constitución no estableció una regulación específica, pero podría haberse buscado una mayor conexión constitucional con el artículo $20 \mathrm{CE}$ en la relación de la libertad de expresión, de información y de comunicación con la democracia, como hacen los Tratados Internacionales, y no sería nada difícil establecer esa interpretación de conformidad con el mandato que establece el artículo 10.2 de la $\mathrm{CE}$ para la interpretación de los derechos fundamentales. ${ }^{31}$

Estos derechos se constituyen en derechos esenciales para cualquier sociedad democrática por cuanto fortalecen las estructuras democráticas de la sociedad, lo que revierte en el fortalecimiento de todas las instituciones democráticas y contribuyen a la presencia de la diversidad. El TEDH lo ha vinculado a la luz del artículo 10 del $\mathrm{CEDH}$, que establece la libertad de expresión, que comprende la libertad de opinión y la libertad de recibir e impartir información e ideas (SSTEDH, de 13 de agosto de 1972, Caso Young y otros vs. Reino Unido; de 20 de septiembre de 1994, Caso Otto Preimnger Institut vs. Austria; de 26 de septiembre de 1995, Caso Vogt, vs. RFA; de 30 de enero de 1998, Caso Partido Comunista Unificado de Turquía y otros vs. Turquía).

${ }^{29}$ Letra h) del artículo 35 redactada por el apartado uno de la disposición final primera de la Ley 19/2013, de 9 de diciembre, de transparencia, acceso a la información pública y buen gobierno («BOE»10 diciembre). Téngase en cuenta que el título preliminar, el título I y el título III entrarán en vigor el día 10 de diciembre de 2014. Vigencia desde el 30 diciembre 2013.

${ }^{30} \mathrm{El}$ artículo 37 de la misma Ley, establece que los ciudadanos tienen derecho a acceder a la información pública, archivos y registros en los términos y con las condiciones establecidas en la Constitución, en la Ley de transparencia, acceso a la información pública y buen gobierno y demás leyes que resulten de aplicación.

${ }^{31}$ ARANDA ÁLVAREZ, E. "Una reflexión sobre trasparencia y buen Gobierno», en Cuadernos Manuel Jiménez Abad, n. ${ }^{\circ}$ 5, junio 2013, pág. 226. 
Incluso hay en la doctrina quien defiende el carácter fundamental del derecho de acceso a la información como derecho vinculado a las libertades informativas, como un derecho subjetivo que surge para afrontar los nuevos retos de la sociedad de la información, de igual forma que ha ocurrido con el derecho fundamental a la protección de datos personales ${ }^{32}$. Su origen como derecho se encontraría en «el tronco común de la libertad de expresión». Sería un derecho directamente relacionado con la transparencia y la lucha contra la corrupción, pero cuyo aspecto más importante es su caracterización como derecho fundamental de última generación que permitirá a la persona participar en la nueva sociedad de la información por medio de la información que le proporcione el Estado ${ }^{33}$.

El CEDH, fuente de interpretación de los derechos constitucionales conforme al artículo 10.2 de la Constitución, no reconoce expresamente el derecho de acceso a la información pública. En diversas ocasiones, se ha planteado ante el Tribunal Europeo de Derechos Humanos si este derecho debe considerarse incluido en el artículo $10 \mathrm{CEDH}$, referido a la libertad de expresión, que comprende la libertad de recibir o de comunicar informaciones o ideas sin que pueda haber interferencias de la autoridad pública. El Tribunal Europeo de Derechos Humanos ya ha dictado varias sentencias reconociendo que el derecho a acceder a la información pública es un derecho fundamental, asumiendo que el derecho de acceso a la información pública forma parte de la libertad de expresión del artículo $10 \mathrm{CEDH}$ (entre otras, SSTEDH Caso Társaság a Szabadságjogokért v. Hungary, de 14 de abril de 2009, Caso Kenedi v. Hungary, de 26 de mayo de 2009, Caso Youth Initiative for Human Rights v. Serbia, de 25 de junio de 2013).

Este enfoque, de hecho, coincide con el de los documentos emanados del Consejo de Europa en forma de recomendaciones o convenios, incluido el Convenio núm. 205 de 2009, que enlazan de modo expreso el derecho de acceso a la información pública con la libertad

32 SÁNCHEZ DE DIEGO, M. «Transparencia y acceso a la información pública ¿son lo mismo? Por un derecho fundamental a acceder a la información pública» en CORREDOIRA Y ALFONSO, L y COTINO HUESO, L. Libertad de expresión e información en Internet. Amenazas y protección de los derechos personales Centro de Estudios Constitucionales. Madrid, 2013. Páginas 283-323. También en «El día después de la Ley de Transparencia» en Revista Jurídica de Castilla y León. n. ${ }^{\circ} 33$. mayo 2014.

33 SÁNCHEZ DE DIEGO, M. «Una nueva libertad de expresión para una nueva sociedad», en Diálogos de la Comunicación (Revista de la Federación Latinoamericana de Facultades de la Comunicación Social) núm. 82, Lima (Perú), septiembre-diciembre de 2010, página 17. 
de expresión consagrada en el artículo $10 \mathrm{CEDH}^{34}$ y con el artículo 19 de la Declaración Universal de Derechos Humanos ${ }^{35}$. Por su parte, en el Derecho comunitario, la Carta de los Derechos Fundamentales de la Unión Europea, consagró asimismo el derecho de acceso como derecho fundamental relacionado con la ciudadanía en su artículo 42, autónomo de la libertad de expresión y del derecho general a recibir información, y figura hoy además en el artículo 15 del Tratado de Funcionamiento de la Unión Europea. El juez comunitario ha puesto de relieve, desde un principio, la vinculación entre derecho de acceso y principio de democracia y transparencia, desde la STJUE de 30 de abril de 1996, Reino de los Países Bajos (apoyado por el Parlamento) contra Consejo, en la que ha puesto de manifiesto que el derecho de acceso a la información tiene por objetivo asegurar una mejor participación de los ciudadanos en el proceso decisorio, así como garantizar una mayor legitimidad, eficacia y responsabilidad de la Administración frente a los ciudadanos en un sistema democrático. Contribuye, así, a reforzar el principio de la democracia y el respeto de los derechos fundamentales ${ }^{36}$.

El acceso a los archivos y registros está relacionado con el derecho de participación política, con el de libertad de información y con el de tutela judicial efectiva, y refleja una concepción de la información que obra en manos del poder público acorde con los principios inherentes al Estado democrático (en cuanto el acceso a los archivos y registros públicos implica una potestad de participación del ciudadano y facilita el ejercicio de la crítica del poder) y al Estado de Derecho (en

34 «1. Toda persona tiene derecho a la libertad de expresión. Este derecho comprende la libertad de opinión y la libertad de recibir o de comunicar informaciones o ideas, sin que pueda haber injerencia de autoridades públicas y sin consideración de fronteras. El presente artículo no impide que los Estados sometan a las empresas de radiodifusión, de cinematografía o de televisión a un régimen de autorización previa.

2. El ejercicio de estas libertades, que entrañan deberes y responsabilidades, podrá ser sometido a ciertas formalidades, condiciones, restricciones o sanciones previstas por la ley, que constituyan medidas necesarias, en una sociedad democrática, para la seguridad nacional, la integridad territorial o la seguridad pública, la defensa del orden y la prevención del delito, la protección de la salud o de la moral, la protección de la reputación o de los derechos ajenos, para impedir la divulgación de informaciones confidenciales o para garantizar la autoridad y la imparcialidad del poder judicial».

${ }^{35}$ Un interesante estudio sobre la jurisprudencia del TEDH en esta materia puede verse en BLASCO ESTEVE A (Coord). El Derecho Público de la crisis económica. Transparencia y sector público. Hacia un nuevo Derecho Administrativo, Madrid, INAP, 2012.

${ }^{36}$ Un aportación importante en el estudio de la naturaleza del acceso a la información puede verse en GUICHOT REINA, E. Transparencia y acceso a la información pública en España: análisis y propuestas legislativas, Laboratorio de Alternativas, Fundación Alternativas, 2011. 
cuanto dicho acceso constituye un procedimiento indirecto de fiscalizar la sumisión de la Administración a la ley y de permitir con más eficacia el control de su actuación por la jurisdicción contenciosoadministrativa)» (SSTS, de 30 de marzo de 1999, y de 19 de mayo de 2003).

Su vinculación con el artículo $20 \mathrm{CE}$ que reconoce el derecho a recibir información veraz es innegable, y este derecho, conforme a la jurisprudencia del TC (STC 159/1986, de 12 de diciembre), determina que "para que el ciudadano pueda formar libremente sus opiniones y participar de modo responsable en los asuntos públicos, ha de ser también informado ampliamente de modo que pueda ponderar opiniones diversas e incluso contrapuestas. (...) La información (...) entraña el reconocimiento y la garantía de una institución política fundamental, que es la opinión pública, indisoluble ligada con el pluralismo político».

La STC 168/1986, de 22 de diciembre, consideró que el derecho a recibir una información veraz es «un instrumento esencial de conocimiento de los asuntos que cobran importancia en la vida colectiva y que, por lo mismo, condiciona la participación de todos en el buen funcionamiento del sistema de relaciones democráticas auspiciado por la Constitución, así como por el ejercicio efectivo de otros derechos y libertades»

La STS de 19 de mayo de 2003 concluyó que: «El artículo 20.1.d) de la Constitución reconoce y protege el derecho a comunicar o recibir libremente información veraz por cualquier medio de difusión. La trascendencia de dicho derecho en un sistema democrático es evidente,

Una Ley de Acceso a la Información es una ley que otorga a los ciudadanos (o a los residentes o partes interesadas) el derecho a conseguir información bajo el resguardo del gobierno, sin la necesidad de demostrar interés legal.

Los principios centrales que deben caracterizar cualquier ley de acceso a la información son ${ }^{37}$ :

1. Apertura máxima: las leyes de acceso a la información deben estar guiadas bajo los principios de máxima apertura informativa.

2. Obligación de publicar: las instituciones públicas deben estar bajo la obligación de hacer pública periódicamente información clave.

${ }^{37}$ Vid. MENDEL, T. Freedom of Information: A Comparative Legal Survey, UNESCO, 2003, New Delhi, India 
3. Promoción de gobiernos abiertos: las instituciones públicas deben auspiciar e impulsar activamente el funcionamiento de gobiernos abiertos.

4. Alcance limitado de las excepciones: las excepciones deben estar clara y estrictamente delimitadas y deben someterse a rigurosas pruebas de «daño social» e «interés público».

5. Eficiencia en el acceso a la información: las solicitudes de acceso a la información deben ser procesadas de forma expedita y justa y debe existir la posibilidad de una revisión independiente de todas las respuestas negativas.

6. Costos: los individuos no deben ser desalentados de exigir la información pública a causa de costos económicos excesivos.

7. Reuniones abiertas: las reuniones de las instituciones públicas deben tener un carácter público y abierto.

8. El principio de apertura debe ser prioritario: las leyes que sean inconsistentes con el principio de máxima apertura informativa deben ser reformadas o abolidas.

9. Protección para informantes: Los interesados en colaborar con información sobre conductas y prácticas incorrectas deben gozar de total protección.

\subsection{La Ley de transparencia, acceso a la información pública y buen gobierno}

La Ley 30/1992, de 26 de noviembre, de Régimen Jurídico de las Administraciones Públicas y del Procedimiento Administrativo Común, estableció que en sus relaciones con los ciudadanos, las Administraciones públicas actúan de conformidad con los principios de transparencia y de participación (art. 35). También la Ley 27/2006, de 18 de julio, por la que se regulan los derechos de acceso a la información, de participación pública y de acceso a la justicia en materia de medio ambiente; la Ley 37/2007, de 16 de noviembre, sobre reutilización de la información del sector público, que regula el uso privado de documentos en poder de Administraciones y organismos del sector público, o la Ley 11/2007, de 22 de junio, de acceso electrónico de los ciudadanos a los Servicios Públicos, inciden en materia de transparencia y, sobre todo, acceso a la información. Sin embargo, esta regulación resulta insuficiente en la actualidad y no satisface las exigencias sociales y políticas del momento. En España, la regulación 
de la transparencia, como se ha hecho en otros países, ha tardado mucho en ser desarrollada.

La ley 19/2013, de 9 de diciembre, de transparencia, acceso a la información pública y de buen gobierno (LTAIBG) reconoce en su Preámbulo, que «La transparencia, el acceso a la información pública y las normas de buen gobierno deben ser los ejes fundamentales de toda acción política. Sólo cuando la acción de los responsables públicos se somete a escrutinio, cuando los ciudadanos pueden conocer cómo se toman las decisiones que les afectan, cómo se manejan los fondos públicos o bajo qué criterios actúan nuestras instituciones podremos hablar del inicio de un proceso en el que los poderes públicos comienzan a responder a una sociedad que es crítica, exigente y que demanda participación de los poderes públicos». Incluso se determina que «una mejor fiscalización de la actividad pública contribuye a la necesaria regeneración democrática, promueve la eficiencia y eficacia del Estado y favorece el crecimiento económico».

El ámbito subjetivo de aplicación de la LTAIBG, recogido en el Capítulo I del Título I, es muy amplio e incluye a todas las Administraciones Públicas, organismos autónomos, agencias estatales, entidades públicas empresariales y entidades de derecho público, en la medida en que tengan atribuidas funciones de regulación o control sobre un determinado sector o actividad, así como a las entidades de Derecho Público con personalidad jurídica propia, vinculadas o dependientes de cualquiera de las Administraciones Públicas, incluidas las Universidades públicas. En relación con sus actividades sujetas a Derecho Administrativo, la Ley se aplica también a las Corporaciones de Derecho Público, a la Casa de Su Majestad el Rey, al Congreso de los Diputados, al Senado, al Tribunal Constitucional y al Consejo General del Poder Judicial, así como al Banco de España, Consejo de Estado, al Defensor del Pueblo, al Tribunal de Cuentas, al Consejo Económico y Social y las instituciones autonómicas análogas. También se aplica a las sociedades mercantiles en cuyo capital social la participación directa o indirecta de las entidades mencionadas sea superior al cincuenta por ciento, a las fundaciones del sector público y a las asociaciones constituidas por las Administraciones, organismos y entidades a las que se ha hecho referencia. Asimismo, se aplicará a los partidos políticos, organizaciones sindicales y organizaciones empresariales y a todas las entidades privadas que perciban una determinada cantidad de ayudas o subvenciones públicas. Por último, las personas que presten servicios públicos o ejerzan potestades administrativas también están obligadas a suministrar a la Administración a la que se encuentren vinculadas, previo requerimiento, toda la in- 
formación necesaria para el cumplimiento por aquélla de las obligaciones de esta Ley. Esta obligación es igualmente aplicable a los adjudicatarios de contratos del sector público.

El primero de los tres ejes básicos de la Ley es, precisamente, el de la Transparencia activa, a la que se dedica un conjunto de artículos que recogen toda aquella información que las instituciones públicas (y las antes citadas entidades privadas) van a tener que publicar de forma obligatoria. Un primer Capítulo está dedicado a delimitar los sujetos que están obligados a suministrar la información, y el segundo Capítulo de este primer Título se refiere a toda aquella información de carácter institucional, organizativa, económica, presupuestaria, etc. que van a tener que publicar las más de 21.400 instituciones públicas existentes en España, así como las otras entidades privadas mencionadas; también se regula en esta primera parte el denominado Portal de Transparencia, que centralizará y facilitará el acceso on-line de los ciudadanos a toda aquella información publicada por los distintos organismos.

Por otra parte, el Acceso a la información pública se recoge en el tercer Capítulo de la Ley, y en él se regula toda aquella información que van a poder solicitar los ciudadanos a las instituciones, así como la forma y los cauces para ejercer ese derecho y llevar a cabo las solicitudes. También se contemplan una serie de causas de inadmisión, la forma y los plazos de las correspondientes resoluciones por parte de las instituciones públicas, así como la creación de unidades de información que permitan instrumentar la recogida y el suministro de esta información a los ciudadanos.

El Título II de la Ley se refiere, por otro lado, al Buen gobierno, siendo la parte de la Ley más relacionada con la prevención de la corrupción, a diferencia de las dos partes anteriores, que están referidas a la transparencia. En este Título se establecen una serie de principios que deberán regir y se deberán asumir por parte de los cargos y mandatarios públicos de cara a evitar o prevenir cualquier tipo de actuación ilegal, relacionada sobre todo con la corrupción. Se establece, por otra parte, un importante régimen de infracciones y sanciones para los casos de incumplimiento de las normas y principios recogidos en este Título, cosa que no existe en relación con los temas de transparencia recogidos en el Título I de la Ley.

La LTAIBG pretende:

- Ampliar y reforzar la transparencia de la actividad pública de la Administración, suministrando información sobre la misma 
(publicidad activa) y garantizando el derecho de acceso a esta información en distintos ámbitos:

a) En materia de información institucional, organizativa y de planificación;

b) En materia de información de relevancia jurídica y que afecte directamente al ámbito de las relaciones entre la Administración y los ciudadanos;

c) En el ámbito de la información de relevancia económica, presupuestaria y estadística;

d) Publicación de toda la información que con mayor frecuencia sea objeto de una solicitud de acceso.

- Establecer las obligaciones de buen gobierno que deben cumplir los responsables públicos así como las consecuencias derivadas de su incumplimiento.

- Regular de forma concreta los derechos de los ciudadanos en el marco de los procedimientos administrativos específicos relativos a cada materia, entre los que destacan el derecho a:

- La no discriminación y a una atención adecuada.

- La buena administración.

- Servicios de calidad.

- Uso de los medios electrónicos.

- La presentación de solicitudes, comunicaciones y otros medios.

- El acceso a los expedientes administrativos, así como a archivos y registros, $\mathrm{y}$

- Una información veraz y de calidad.

- Fomentar, con carácter general, el uso de los medios electrónicos y telemáticos para garantizar el mantenimiento íntegro de los derechos de los ciudadanos ante la actuación de las Administraciones Públicas, el cual deberá basarse en los principios de igualdad, accesibilidad, neutralidad y seguridad.

En el desarrollo de la transparencia y buen Gobierno, la Ley defiende los siguientes principios:

a. Principio de publicidad y derecho de acceso a la información pública. La publicidad se configura como un instrumento para fomentar y promover el principio de transparencia a 
través del ejercicio del derecho de acceso a la información pública.

b. Principio de buen gobierno. Se denomina buen gobierno a la forma de actuar que debieran observar los líderes políticos, las instituciones públicas, la Administración y los servicios públicos, así como todas las personas que lleven a cabo una acción de gestión o de gobierno en entidades privadas que prestan servicios públicos. Dicha actuación deber ser, en cualquier caso, ajustada al ordenamiento jurídico y a los referentes morales y éticos operantes en nuestra sociedad

c. Principio de participación ciudadana. La participación ciudadana en la vida pública se configura como un derecho en los artículos 9.2, 27.5, 29.1 y $105 \mathrm{CE}$, viniendo las Administraciones públicas obligadas a promover y garantizar la efectiva participación de los ciudadanos en la vida administrativa en cumplimiento del referido mandato constitucional

De acuerdo con el artículo 12, todas las personas tienen derecho a acceder a la información pública, en los términos previstos en el artículo 105.b) CE, entendiéndose por información pública los contenidos o documentos, cualquiera que sea su formato o soporte, que obren en poder de alguno de los sujetos incluidos en el ámbito de aplicación de este título y que hayan sido elaborados o adquiridos en el ejercicio de sus funciones.

No obstante la importancia de esta nueva legislación, también ha sido sometida a una importante crítica.

A pesar de ese importante papel de avance social de la Ley, no va a ser en absoluto la mejor ley posible, ya que la misma contiene una serie de deficiencias que no se han subsanado en su tramitación parlamentaria final, debido, sobre todo, a que el conjunto de los partidos políticos no han sabido estar a la altura de las circunstancias, y no han hecho los esfuerzos necesarios para alcanzar los correspondientes pactos o acuerdos en materia de transparencia, tan importante y tan demandada por la ciudadanía y la sociedad de este país. Además de no reconocer el derecho de acceso a la información como un derecho fundamental, son muchas las críticas que ha recibido la ley: tiene un alcance limitado (solo podemos acceder a información administrativa), excluye tipos de información (informes y comunicaciones internos quedan fuera), hay un doble silencio administrativo negativo (la administración puede no contestar y el Consejo de la transparencia 
también puede no contestar ${ }^{38}$ ) y el nombramiento del Presidente del Consejo de la Transparencia lo hace el Ministro de Hacienda (lo que arroja legítimas dudas sobre su independencia).

Sobre el derecho de acceso a la información, además de los límites que aporta el texto de la ley, el Gobierno ha optado por un sistema de solicitud complejo que obliga a registrarse y a presentar el DNI. Hay cuatro opciones para registrarse, y todas implican tener un ordenador, internet y si no tienes certificado digital o DNIe, un móvil; dejando fuera a aquellos que no dispongan de estos dispositivos.

No se contemplan clara y explícitamente en la nueva Ley infracciones ni sanciones a políticos y funcionarios públicos por el incumplimiento de las normas de transparencia.

En relación al Consejo de Transparencia y Buen Gobierno, creemos que es un órgano que ha nacido con un notable déficit de independencia. En primer lugar, porque el Presidente es nombrado por el Gobierno, y su refrendo parlamentario exige la mera aplicación de la mayoría parlamentaria; hubiera sido conveniente de cara a asegurar un adecuado nivel de consenso que su nombramiento hubiera haberse aprobado por mayoría parlamentaria cualificada. Por otra parte, pensamos que el Consejo de Transparencia hubiera tenido unos mayores visos de objetividad e independencia si en su composición se hubiese dado entrada a representantes de la oposición parlamentaria, así como a representantes de organismos de la sociedad civil que promueven la transparencia y el buen gobierno.

Respecto a los límites, el Tribunal Supremo español ha subrayado, en su Sentencia de 6 de junio de 2005, que las excepciones legales al derecho de acceso a archivos y registros públicos «han de estar justificadas en términos constitucionalmente aceptables», y en la Sentencia de 16 de diciembre de 2011, añade que es exigible «una interpretación favorable al ejercicio del derecho de acceso a los documentos administrativos». En sentido idéntico se ha pronunciado el TJUE en el asunto Access Info Europe/Consejo de 2009, indicando que: «El acceso del

${ }^{38}$ Se establece en la Ley un régimen de Silencio administrativo negativo, que respeta muy poco el derecho de los ciudadanos a tener una respuesta explícita, de un tipo o de otro, por parte de la Administración, y que hace que en la práctica, si las instituciones públicas no desean contestar a las solicitudes de información, éstas se entienden simplemente denegadas transcurrido el plazo estipulado de un mes. Debería haberse incluido expresamente en la Ley la obligación de las instituciones públicas a contestar o resolver las solicitudes recibidas en el citado plazo, o aún después de vencido dicho plazo, fijándose alguna sanción disciplinaria (apercibimiento, multa, o suspensión de empleo y sueldo, por ejemplo) para el funcionario público o responsable que no cumpliera con la petición en tiempo sin motivo justificado. 
público a los documentos de las instituciones constituye el principio y la denegación la excepción, que debe interpretarse restrictivamente ${ }^{39}$.

El derecho de acceso, de acuerdo con el artículo 14 LTAIBG, podrá ser limitado cuando acceder a la información suponga un perjuicio para: a) la seguridad nacional; b) la defensa; c) las relaciones exteriores; d) la seguridad pública; e) la prevención, investigación y sanción de los ilícitos penales, administrativos o disciplinarios; f) la igualdad de las partes en los procesos judiciales y la tutela judicial efectiva; g) las funciones administrativas de vigilancia, inspección y control; h) los intereses económicos y comerciales; i) la política económica y monetaria; j) el secreto profesional y la propiedad intelectual e industrial; k) la garantía de la confidencialidad o el secreto requerido en procesos de toma de decisión, y l) la protección del medio ambiente.

No obstante, la aplicación de los límites será justificada y proporcionada a su objeto y finalidad de protección y atenderá a las circunstancias del caso concreto, especialmente a la concurrencia de un interés público o privado superior que justifique el acceso.

Las resoluciones que se dicten en aplicación del artículo 14 serán objeto de publicidad, previa disociación de los datos de carácter personal que contuvieran y una vez hayan sido notificadas a los interesados.

Con carácter general, y salvo que en el caso concreto prevalezca la protección de datos personales u otros derechos constitucionalmente protegidos sobre el interés público en la divulgación que lo impida, se concederá el acceso a información que contenga datos meramente identificativos relacionados con la organización, funcionamiento o actividad pública del órgano. Cuando la información solicitada no contuviera datos especialmente protegidos, el órgano al que se dirija la solicitud concederá el acceso previa ponderación suficientemente razonada del interés público en la divulgación de la información y los derechos de los afectados cuyos datos aparezcan en la información solicitada, en particular su derecho fundamental a la protección de datos de carácter personal. Para la realización de la citada ponderación, dicho órgano tomará particularmente en consideración los siguientes criterios:

a) El menor perjuicio a los afectados derivado del transcurso de los plazos establecidos en el artículo 57 de la Ley 16/1985, de 25 de junio, del Patrimonio Histórico Español.

${ }^{39}$ Anteriormente, otras decisiones de la jurisprudencia comunitaria han abundado en esta misma línea. Cfr. Petrie y otros/Comisión T-191-99, de 11 de diciembre de 2001, apartado 66; Bavarian Lager/Comisión, T-309/97, de 14 de octubre de 1999, apartado 39; Interporc Im-und Export GMBH/Comisión, C-41/00 P, de 6 de marzo de 2003; Olli Mattila, C-353/01 P, de 22 de enero de 2004, entre otras. 
b) La justificación por los solicitantes de su petición en el ejercicio de un derecho o el hecho de que tengan la condición de investigadores y motiven el acceso en fines históricos, científicos o estadísticos.

c) El menor perjuicio de los derechos de los afectados en caso de que los documentos únicamente contuviesen datos de carácter meramente identificativo de aquéllos.

d) La mayor garantía de los derechos de los afectados en caso de que los datos contenidos en el documento puedan afectar a su intimidad o a su seguridad, o se refieran a menores de edad.

\section{TRANSPARENCIA INTERNACIONAL. LA PERCEPCIÓN DE CORRUPCIÓN EN EL MUNDO. EL CASO ESPAÑOL}

La transparencia es un concepto más amplio que la lucha anticorrupción. El comité de Transparencia de la OECD la definió como «el proceso por el cual la información de las condiciones existentes permite ser accesada para la toma de decisiones y acciones, de manera visible y entendible» ${ }^{40}$.

Transparencia Internacional (TI) es la única organización no gubernamental a escala universal dedicada a combatir la corrupción, congregando a la sociedad civil, sector privado y los gobiernos en una amplia coalición global ${ }^{41}$.

TI elabora el Índice de Percepción de la Corrupción (IPC), que evalúa la corrupción en el mundo ${ }^{42}$, pero en la idea de que el índice está destinado para medir la percepción de la corrupción no la realidad, y ello es especialmente grave, puesto que afecta a la toma de

${ }^{40}$ Vid. FLORINI, A. The Battle over Transparency. The Right to Know: Transparency for an Open World. Initiative for Policy Dialogue Columbia University, 2007.

${ }^{41}$ Todos los datos que se ofrecen en este trabajo pueden consultarse en la página web de Transparencia Internacional: https://www.transparency.org. Informe: «Corruption Perceptions Index 2014: Results». Transparency International. 2014. Consultado el 14 de junio de 2015.

${ }^{42}$ El Îndice de Percepción de la Corrupción (IPC) se creó en 1995 como un indicador compuesto utilizado para medir las percepciones sobre corrupción en el sector público, en distintos países de todo el mundo. Durante los últimos 18 años, tanto las fuentes empleadas para compilar el índice como la metodología se han ido modificando y perfeccionando. El último proceso de evaluación se efectuó en 2012 y se incorporaron algunos cambios importantes a la metodología. El método que se utilizó hasta 2012 para combinar las distintas fuentes de datos se ha simplificado, y ahora incluye los datos correspondientes a períodos de solamente un año de cada fuente de datos. En todo caso, este método permite ahora comparar las puntuaciones en el tiempo, una posibilidad que la metodología previa a 2012 no admitía. 
decisiones, sobre la base de la percepción, lo que atenta de manera grave a la democracia ${ }^{43}$.

La metodología comprende cuatro pasos básicos: seleccionar las fuentes de datos, ajustar la escala de las fuentes de datos, combinar las fuentes de datos y luego determinar una medida de incertidumbre.

Para la selección de las fuentes de datos ${ }^{44}$, cada fuente se evalúa teniendo en cuenta los siguientes criterios:

A) Instituciones creíbles con metodologías y mecanismos de recolección de datos confiables.

B) Datos vinculados con la corrupción en el sector público.

C) Precisión cuantitativa.

D) Comparabilidad entre países.

E) Conjunto de datos correspondientes a varios años.

Los resultados del IPC a nivel internacional del año 2014, muestran como en esta vigésima edición del Índice de Percepción de la Corrupción, más de dos tercios de los 175 países incluidos en el mismo han obtenido una puntuación inferior a 50, en una escala de 0 (percepción de altos niveles de corrupción) a 100 (percepción de bajos niveles de corrupción). Dinamarca y Nueva Zelanda se sitúan en las dos primeras posiciones de 2014, con una puntuación de 92 y 91 respectivamente, mientras que Corea del Norte y Somalia comparten el último lugar, con sólo 8 puntos.

Dinamarca, que ostenta el mejor resultado del índice, demuestra una profunda consolidación del Estado de Derecho, apoyo a la sociedad civil y normas claras que regulan la actuación de quienes ocupan funciones públicas, y ha adoptado, a su vez, una medida ejemplar en

${ }^{43}$ Vid. USLANER, E. M. Corruption, inequality, and the rule of law: the bulging pocket makes the easy life, Cambridge University Press, 2008.

${ }^{44}$ Para elaborar el Índice de Percepción de la Corrupción 2014 se han utilizado 12 fuentes de datos: 1. Calificaciones sobre Gobernabilidad 2013 del Banco Africano de Desarrollo; 2. Indicadores sobre Gobernabilidad Sostenible 2014 de Bertelsmann Foundation; 3. Índice de Transformación 2014 de Bertelsmann Foundation; 4. Calificaciones de Riesgo País 2014 de la Economist Intelligence Unit; 5. Naciones en Transición 2014 de Freedom House; 6. Calificaciones de Riesgo País 2014 de Global Insight; 7. Anuario de Competitividad Mundial 2014 de IMD; 8. Political and Economic Risk Consultancy Asian Intelligence 2014; 9. Guía Internacional sobre Riesgo País 2014 de Political Risk Services; 10. Evaluación Institucional y de las Políticas Nacionales 2013 del Banco Mundial; 11. Encuesta de Opinión Ejecutiva (EOE) 2014 del Foro Económico Mundial; 12. Índice de Estado de Derecho 2014 de World Justice Project. 
noviembre, al anunciar que prevé crear un registro público con información sobre propietarios y titulares finales de todas las sociedades constituidas en ese país. Esta medida, similar a aquellas anunciadas por el Reino Unido y Ucrania, significará mayores escollos para los corruptos que pretendan ocultarse detrás de sociedades constituidas en nombre de terceros.

Por otra parte, la puntuación de varios países ha tenido un aumento o descenso de al menos cuatro puntos. Los descensos más marcados son los de Turquía (-5), así como Angola, China, Malawi y Ruanda (todos ellos -4), ello a pesar de haber tenido en algunos casos un crecimiento económico promedio de más del 4 por ciento en los últimos cuatro años. Las mejoras más notables son las de Costa de Marfil, Egipto, San Vicente y las Granadinas (+5), Afganistán, Jordania, Mali y Suazilandia (+4).

La puntuación de China ha bajado de 40 en 2013 a 36 en 2014, a pesar de que el gobierno de ese país ha puesto en marcha una campaña para erradicar la corrupción entre funcionarios públicos. También se observan graves problemas de corrupción y lavado de dinero en algunos países. Este año ha trascendido que una de las principales compañías petroleras habría utilizado sociedades secretas para sobornar a políticos en Brasil (que obtuvo una puntuación de 43), que personas de India (38) utilizan cuentas bancarias en Mauricio (54) y que ciudadanos rusos (27) hacen lo mismo en Chipre (63).

\subsection{Los resultados de España en el IPC 2014}

España ha venido a consolidar en el IPC 2014 la puntuación que recibió en 2013, dado que este año obtiene una puntuación similar (60) a la de 2013 (59). El año pasado nuestro país descendió 10 puestos en este Índice (hasta el puesto 40 del ranking global), este año está en el puesto 37 entre los 175 países analizados, subiendo 3.

España no tiene corrupción sistémica, como ocurre en un gran número de países, sino múltiples escándalos de corrupción política en los niveles superiores de los partidos y en los gobiernos locales y autonómicos.

Estas puntuaciones de 2013 y 2014 suponen la continuación en el cambio de ciclo que se inició a partir de la crisis económica, que hizo que España pasase, paulatinamente, de puntuaciones de 7,1 a puntuaciones inferiores. Situarse en torno al 6 es algo que ya se puede comprobar en los niveles mostrados por España en los años anterio- 
res, ya que venía mostrando unas puntuaciones relativamente estables: en 2009 obtuvo una puntuación de 6,1 sobre 10, en 2010 también 6,1 sobre 10, en 2011: 6,2 sobre 10, y en 2012: 6,5 sobre 100; sin embargo, es cierto que en estas dos últimas ediciones ha alcanzado las puntuaciones más bajas en los últimos quince años.

Las razones de este descenso en los dos últimos años son complejas; por una parte, los sistemas de control se han mostrado más eficaces y han venido aflorando numerosos casos de corrupción; por otra parte, las denuncias de los medios de comunicación y el relevante eco social y atención prestada a los casos ahora aflorados han influido intensamente en la percepción ciudadana, generando un estado general de indignación; también es cierto que la crisis económica ha incrementado el nivel de exigencia social, y aunque la justicia viene cumpliendo su función con cierta eficacia y nivel de resultados, a pesar de su lentitud, se ha generado desde finales de 2009 un alto nivel de alarma social; finalmente, aunque el enfriamiento de la economía, especialmente en el sector urbanístico, permite pensar que los casos de corrupción se han reducido en ese ámbito, la lentitud de las sanciones penales, la baja intensidad de las penas en casos de corrupción relevante, la expansión de los escándalos a las instituciones clave del Estado, y la sensación de impunidad explican bien la percepción social negativa que se mantiene en este Índice.

La ley de transparencia en España tiene solo un año de vida. En el "Global Right to Information Rating», elaborado por las organizaciones pro transparencia Centre for Law and Democracy y Acces Info a partir de 61 indicadores, España, y su ley, ocupan el puesto 64 de 100 países.

La legislación marca plazos en el ámbito territorial. Las comunidades autónomas y Ayuntamientos tienen hasta diciembre de 2015 para ordenar y presentar información pública, como contratos, sueldos, bienes inmuebles y subvenciones. Algunas ya lo hacen y la valoración media, según TI, es de 88,6 puntos sobre 100. Según sus últimos datos, de 2014, Castilla y León, Cataluña y el País Vasco son las regiones más transparentes; Madrid (65), Murcia (79) y Canarias (80). Las menos, Asturias, Cantabria, Castilla-La Mancha, Madrid y Baleares, aún carecen de legislación sobre transparencia, y Madrid es la única sin portal de transparencia hasta el momento. 
En el ámbito local, donde la transparencia ha mejorado cualitativamente $^{45}$, un estudio que ha recopilado datos de 110 Consistorios, refleja una mejora progresiva en materia de transparencia. Un total de 19 corporaciones locales obtuvieron la máxima puntuación; y $102(92,7 \%)$ aprobó $^{46}$.

En España «... podemos afirmar que la corrupción percibida es bastante mayor que aquella que los datos sustentan. Por otra parte, la corrupción mayoritariamente existente en España es corrupción política y no funcionarial. También como es lógico, lo es la corrupción más grave. Los datos objetivos, con todos sus problemas de cómputo y definición son bastante claros al respecto. La corrupción administrativa es baja, aunque esto puede deberse en parte, a la debilidad de la política de represión de los delitos contra la Administración. La corrupción política, aunque no es tan alta como pueda parecer, si nos centramos en los medios de comunicación, supera con mucho en números relativos y gravedad a la corrupción puramente

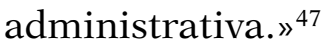

Sin embargo, sería importante, además de la aprobación de la ley, y de la creación de los Portales de transparencia, adoptar algunas medidas «inmediatas», de "choque», que ayuden a atenuar el evidente nivel de indignación ciudadana frente a la corrupción, entre las que TI destaca:

- Detallar las cuentas de los partidos políticos en Internet.

- Publicar el informe de auditoría anual del Tribunal de Cuentas a los partidos políticos.

- Dar publicidad a los préstamos otorgados a los partidos y prohibir por ley que las entidades financieras puedan condonárselos.

${ }^{45} \mathrm{Vid}$. LIZCANO ÁLVAREZ, J. La transparencia en el ámbito municipal: una experiencia proactiva desde la sociedad civil, en AECA: Revista de la Asociación Española de Contabilidad y Administración de Empresas, N. ${ }^{\circ}$ Extra 87, 2009.

${ }^{46} 19$ Ayuntamientos han copado el primer puesto del ranking, con una nota de 100 puntos sobre 100: Alcalá de Henares, Alcobendas, Alcorcón, Badalona, Barcelona, Bilbao, Getxo, Guadalajara, Lleida, Móstoles, Oviedo, Palma de Mallorca, Sabadell, San Cugat del Vallés, Soria, Torrejón de Ardoz, Torrent, Vitoria y Zaragoza. Los últimos en el ranking son Algeciras (puesto 101), Marbella (102), Elche (103), Pontevedra (104), Telde (105), Teruel (106), Jaen (107), Badajoz (108), Almería (109) y Granada (110).

${ }^{47}$ VILLORIA, M. y JIMENEZ, F.: «La corrupción en España (2004-2010): datos percepción y efectos» en Revista Española de Investigaciones Sociológicas, n. ${ }^{\circ} 138$, abril-junio 2012, pág. 128 y ss. 
- Prohibir, tanto a los partidos como a las fundaciones asociadas a ellos, todas las donaciones procedentes de personas jurídicas o empresas que reciban subvenciones públicas, sean reguladas por o necesiten licencias de la Administración.

- Que se tipifique jurídicamente el delito de financiación ilegal de los partidos políticos.

- Que se establezca un «procedimiento normalizado de auditoría interna» por parte de los partidos políticos y que la misma se haga pública.

- Que sea obligatorio publicar y debatir en el Parlamento todos los casos de alto endeudamiento.

- La modificación del sistema electoral «para que el ciudadano tenga una mínima capacidad de decisión» a través de listas abiertas en las que puedan excluir o cambiar, al menos, el orden de alguno de los candidatos de la lista (listas abiertas).

- Apartar del partido a todos los procesados por corrupción, que sea obligatorio publicar los currículos y datos biográficos de todos los candidatos incluidos en listas electorales.

- Que se controle «estrictamente» el cumplimiento de los límites en los gastos electorales y que se impongan sanciones a todos los partidos que los incumplan.

- Cualquier condena por delitos asociados a la corrupción debe conllevar la inhabilitación por un largo periodo para volver a ocupar un cargo público.

- Limitar los mandatos para evitar que la política «sea un modus vivendi». Los ciudadanos que denuncien posibles casos de corrupción deben estar amparados por una ley de protección jurídica.

— Despolitización del Tribunal de Cuentas.

- Nuevo modelo de elección del Consejo del Poder Judicial.

— Deben limitarse los «privilegios jurídicos» de los aforados, y su número, para evitar «un cierto espacio de impunidad» «estableciendo límites a su designación por los partidos políticos».

- Menos indultos y nunca para corrupción.

- Introducir en el sistema educativo «materias y contenidos éticos, de valores y contra la corrupción». 
- Pacto general contra la corrupción para «corregir y encauzar la grave situación y la alarma social actualmente existente».

La transparencia no son solo leyes o investigaciones, la transparencia es, sobre todo, una cultura. La transparencia no basta si no va unida a la rendición de cuentas y al seguimiento constante y en tiempo real de la actividad de los gobiernos y los parlamentos para poder, también, evaluar con seriedad las políticas ${ }^{48}$.

${ }^{48}$ Vid. LIZCANO ÁLVAREZ, J. «La transparencia como indicador del progreso social», en Consejeros: la revista del buen gobierno y la responsabilidad corporativa, N. ${ }^{\circ} 57$ (enero), 2011. 
